\title{
AUSTRALIAN LIVE ANIMAL EXPORT: A COMPARATIVE EXAMINATION OF VIABLE ALTERNATIVES
}

\author{
SEAMUS BRAND
}

The Australian live animal export trade has long been under scrutiny due to repeated public outcries over the animal welfare abuses that are seemingly intrinsic to the trade. This article examines the regulatory regimes of Australia's international competitors and asks whether Australian authorities should adopt their solutions to the problem of protecting the welfare of animals who are exported live to other nations. The article begins by providing an overview of the current Australian regulatory framework in Part II. Parts III and IV discuss the approaches taken by two of Australia's international competitors in the animal export trade, New Zealand and Brazil. Part $V$ examines the merits of a proposed international treaty governing animal welfare worldwide and asks whether such an umbrella treaty can create a more focused global standard for both live animal export and import nations. It concludes that Australia must follow the lead of Brazil and New Zealand by crafting a new regime that protects the welfare of export animals, while simultaneously sponsoring the creation of a multilateral animal welfare treaty.

\section{CONTENTS}

I Introduction.

2

II The Current Australian Framework.

3

III The New Zealand Approach 6

A Model for Australia? ............................................................ 8

IV Brazil Strides Forward ................................................................ 10

V The Future - A Multilateral Treaty ....................................................12

A The Construction of the Treaty ............................................13

B Adapting the Treaty by Altering the Focus ...........................15

VI Conclusion................................................. 16

LLB student, School of Law, University of South Australia. 


\section{INTRODUCTION}

The Australian contribution to the live animal export industry is the largest of any nation. ${ }^{1}$ Unfortunately, Australia also has one of the worst records for animal welfare abuse within the industry. Originally these abuses were traced to a lack of government regulation, which allowed poor conditions during transport. ${ }^{2}$ Recent reports, however, indicate that the abuses have continued 'beyond the ships' and into the abattoirs of the importing nations. ${ }^{3}$ The Australian Government responses eventually led to the creation of a comprehensive domestic legislative scheme, ${ }^{4}$ however, the international regulation is demonstrably inadequate and requires a long term solution.

Across the Tasman, New Zealand leads the international community in maintaining and controlling animal welfare standards across the breadth of live export. ${ }^{5}$ Further west, Brazil constitutionally enshrines animal welfare ${ }^{6}$ and is investing millions of US dollars into improving standards. ${ }^{7}$ Neither of these countries can claim to have a live animal exporting experience substantially different from that of Australia; indeed, all three nations reacted to animal welfare abuses when they occurred during past incidents in the course of the trade. One noticeable difference, however, relates to the

1 Meat and Livestock Australia, Sheep Industry Projections - Live Sheep Exports (January 2013) Meat and Livestock Australia <http://www.mla.com.au/Prices-and-markets/Trendsand-analysis/Sheepmeat-and-lamb/Forecasts/MLA-sheep-industry-projections-2013>.

2 Senate Select Committee on Animal Welfare, Parliament of the Commonwealth of Australia, Export of Live Sheep from Australia (1985); Livestock Export Review, Final Report, report to the Minister for Agriculture, Fisheries and Forestry, 23 December 2003.

3 The Senate Rural Affairs and Transport Committee, Parliament of Australia, 'Animal Welfare Standards in Australian Live Export Markets' (2011).

4 See below: II The Current Australian Framework.

5 Marie T Hastreiter, 'Animal Welfare Standards and Australia's Live Exports Industry to Indonesia: Creating an Opportunity out of a Crisis' (2013) 12 Washington University Global Studies Law Review 181.

6 Republica Federativa de Brasil Constitucion Politica de 1988, con reformas de 1996, em ingles (Federative Republic of Brazil 1988 Constitution, with 1996 reforms in English) (Brazil), Chapter VI, Article 225

$<$ http://www.stf.jus.br/repositorio/cms/portalstfinternacional/portalstfsobrecorte_en_us/anex o/constituicao_ingles_3ed2010.pdf $>$.

7 Monika Merkes and Robb Buttrose, Brazil Kicking Goals on Animal Welfare (14 July 2014) La Trobe University <http://www.latrobe.edu.au/news/articles/2014/opinion/brazil-kickinggoals-on-animal-welfare $>$. 
conviction with which New Zealand and Brazil responded: New Zealand worked to end the trade over time, while Brazil invested heavily in improving its animal export protocols after accusations of poor animal welfare. ${ }^{8}$

This article discusses the different approaches taken by New Zealand and Brazil in improving animal welfare within the live animal export trade and considers how these mechanisms and initiatives may be implemented in the Australian industry. Part II provides an overview of the current Australian regulatory framework; and Parts III and IV discuss the approaches taken by two of Australia's international competitors in the animal export trade, New Zealand and Brazil. Part V examines the merits of a proposed treaty for worldwide animal welfare and explores the capacity of such a treaty to create a more focused global standard for both live animal export and import nations. Ultimately, this article concludes that Australia must use the initiative of Brazil to create the New Zealand solution, while simultaneously sponsoring the creation of a multilateral animal welfare treaty.

\section{THE CURRENT AUSTRALIAN FRAMEWORK}

Over the past 12 years, the evolution of the regulation of animal welfare in the Australian live animal export trade has sparked controversy. Reactive media coverage and public outcry have forced legislative action to prevent further animal welfare abuses, at first during transit ${ }^{9}$ and later upon arrival in the destination nation. ${ }^{10}$ With successive governments unwilling to sacrifice the $\$ 1$ billion a year industry ${ }^{11}$ by suspending the trade entirely, the issue remains pressing. The government responses to both the $M V$ Cormo Express incident ${ }^{12}$ and the 'A Bloody Business' television exposé, ${ }^{13}$ have, however, shown a desire to further regulate the industry in order to create a better standard of animal welfare. To date the government has not looked to an

8 Ibid.

9 Department of Agriculture, Fisheries and Forestry, Australian Standards for the Export of Livestock (Version 2.3) 2011.

10 Department of Agriculture, Exporter Supply Chain Assurance System (ESCAS) (25 February 2015) Australian Government Department of Agriculture.

11 Meat and Livestock Australia, Sheep Industry Projections - Live Sheep Exports (January 2013) Meat and Livestock Australia. <http://www.mla.com.au/Prices-and-markets/Trendsand-analysis/Sheepmeat-and-lamb/Forecasts/MLA-sheep-industry-projections-2013>.

12 Michelle Grattan, 'Sheep Onboard a National Shame', The Age (online), 24 September 2003 $<$ http://www.theage.com.au/articles/2003/09/23/1064082991895.html>.

13 ABC Television, 'A Bloody Business', Four Corners, 30 May 2011, Sarah Ferguson $<$ http://www.abc.net.au/4corners/content/2011/s3230934.htm>. 
answer in international law, has not invested significant resources, and has not looked across the Tasman for inspiration on diversification and eventual cessation of the trade.

Thus far, the Australian regulatory solution to the live animal export question has been an ad hoc patchwork effort prompted by public outrage. While the industry was self-regulated from its beginning in $1895^{14}$ and through the market boom of the $1970 \mathrm{~s},{ }^{15}$ a shift away from this self-regulation began in 2003 as a consequence of the Live Export Review. ${ }^{16}$ This Commonwealthordered review was a reaction to the MV Cormo Express incident, where 6 000 sheep died on board a live export vessel that was rejected at its intended port in Saudi Arabia. ${ }^{17}$ The review eventually led to the first Commonwealth iteration of the Australian Standards for the Export of Livestock ('ASEL') in $2005,{ }^{18}$ which replaced previous standards that had been set by Livecorp, the industry's own regulatory body. ${ }^{19}$ These standards were flawed from the outset; they were created without any parliamentary debate and without including any set definition of 'animal welfare'.

While the ASEL appears to have improved on-board conditions for live export animals, it failed to prevent further instances of animal abuse. In 2011 the ABC program Four Corners detailed the conditions in the abattoirs of Australia's largest live animal trade partner, Indonesia. ${ }^{20}$ The conditions of slaughter and general care were barbaric and the ensuing public outcry demanded government action. The result was a two month suspension of the trade and the creation of the Senate Standing Committee on Rural Affairs and Transport, Animal Welfare Standards in Australian Live Export Industry, 2011. This committee was more focused than the previous review, and recommended greater dialogue with live export partners and the

14 Senate Select Committee on Animal Welfare, Parliament of the Commonwealth of Australia, Export of Live Sheep from Australia (1985) 3.

15 Ibid. Livestock Export Review, Final Report, report to the Minister for Agriculture, Fisheries and Forestry, 23 December 2003.

17 Grattan, above n 12.

18 Department of Agriculture, Fisheries and Forestry, Australian Standards for the Export of Livestock (Version 2.3) 2011. Australian Government Response, Senate Rural Affairs and Transport References Committee July 2012

20 'A Bloody Business', above n 13. 
implementation of multilateral protocols aimed at improving animal welfare across the board. ${ }^{21}$

The legislative framework resulting from these two reviews is less than ideal. Two statutes govern the trade within Australia, the Export Control Act 1982 (Cth) and the Australian Meat and Livestock Industry Act 1997 (Cth) ('AMLI Act'). A third, the Navigation Act 1912 (Cth), comes into force once the livestock have left the nation. Any person wishing to engage in live animal export must first apply for an export licence under s 11 of the AMLI Act, and the Secretary of Agriculture may then grant the licence in writing under s 10 . The terms of this licence are uniform, prescribed by the Australian Meat and Livestock Industry (Export Licensing) Regulations 1998 (Cth) and requiring compliance with ASEL. Any failure to comply with the export licence is considered a strict liability offence, resulting in a fine of up to $\$ 50000$ and revocation of the export licence. ${ }^{22}$

After the Senate Committee report noted above, a further condition was imported into all export licences requiring compliance with the Exporter Supply Chain Assurance System ('ESCAS'). In essence, ESCAS operates to create a farm-to-killing-floor assurance of animal welfare by placing a greater onus on the exporter to ensure that the animal welfare conditions inside the importing nation are at an acceptable standard. ${ }^{23}$ The backbone of this assurance is the independent audit of the supply chain in the importing nation. ${ }^{24}$ However, ESCAS cannot be said to succeed on this point, as there is no independent Government body responsible for these audits, and the audits are paid for by the exporters themselves. The conflict of interest is clear and no countermeasures currently exist to prevent abuse of this situation. Despite the long history and two Government reviews into the trade, Australia has ultimately failed in regulating the live animal export industry to any acceptable standard of animal welfare.

21 The Senate Rural Affairs and Transport Committee, Parliament of Australia, Animal Welfare Standards in Australian Live Export Markets (2011) ix-x.

23 Department of Agriculture, Exporter Supply Chain Assurance System (ESCAS) (25 February 2015) Australian Government Department of Agriculture

$<$ http://www.agriculture.gov.au/export/live-animals/livestock/information-exportersindustry/escas? wasRedirectedByModule $=$ true $>$. 


\section{THE NEW ZEALAND APPROACH}

The live animal export trade in New Zealand recommenced in 1985 after several years of a total ban. ${ }^{25}$ While the reasons for this initial ban are not clear, the renewed trade was subject to quotas set by a government advisory committee in order to 'satisfy the animal welfare lobby and domestic slaughter industry. ${ }^{26}$ In 1988, this quota method was left behind and an approval system for each shipment by the Minister of Agriculture and later Ministry of Agriculture and Forestry's (the Department) Chief Veterinary Officer was adopted. ${ }^{27}$ This approach mirrors the current Australian export licensing scheme. ${ }^{28}$

The export approval system was used consistently during the expansion of the trade to Saudi Arabia, where a ban from the Australian authorities had created a gap in the market that was easily filled by New Zealand livestock. ${ }^{29}$ In 1990, a 1 per cent mortality rate among the live sheep on board the $M V$ Cormo Express en route to Saudi Arabia, and the rejection of the sheep on board the Mawashi Al Gasseem by a Saudi Arabian port due to disease that caused thousands of deaths in the 16 weeks before unloading, led to a public outcry in New Zealand. ${ }^{30}$ New Zealand suspended its live sheep trade with Saudi Arabia and the ban continued until discussions with Saudi authorities led to recommencement of trade in $1991 .^{31}$ The market peaked in the mid-90s 'with over one million sheep being exported annually.' ${ }^{32}$ Thus far, the similarity to the Australian experience is startling. The MV Cormo Express was, indeed, the same boat that sparked the Australian discussion on the trade in $2003 .^{33}$ The temporary suspension of the New Zealand trade in response to

25

ACIL Tasman, Australian Live Sheep Exports, Economic Analysis of Australian Live Sheep and Meat Trade, September 2009 (Melbourne, Australia), 64.

26

27

Ministry for Primary Industries, Steps to Exporting (5 March 2015) Ministry for Primary Industries <http://www.mpi.govt.nz/exporting/animals/live-animals/steps-to-exporting-liveanimals $>$.

28

0

Asa Lind, 'Live Sheep Exports and Animal Welfare: An Impossible Match' (2004) Live Export Shame $<\mathrm{http}: / / \mathrm{www}$. liveexportshame.com/impossible match.htm>.

31 ACIL Tasman, above n 25, 65.

32 Ibid.

33 
allegations of animal welfare abuse is nearly identical to the Australian response to the 'A Bloody Business' report.

It appears that the pattern of abuse and public outrage, which, in turn, prompts a government response, is not isolated to Australia and is intrinsically tied to the live animal export trade. In 1991, when renewing the trade, New Zealand implemented the Animal Welfare Advisory Committee Code that sought to establish acceptable welfare standards aboard live animal export ships and reduce mortality rates on-board to below 1 per cent. ${ }^{34}$ In order to achieve this goal, a Department approved veterinarian accompanied every shipment and a broad reporting system allowed the Department to review each consignment. ${ }^{35}$ This system is, again, startlingly similar to the Australian response. The Australian response established the Australian Standard for Export of Livestock Version 2.3 (2011), which implemented nearly identical protocols and mortality rate requirements. While there are scant statistics on the success of the Australian system (apart from a lack of any further animal cruelty exposés), the New Zealand scheme managed to hold the mortality rate consistently below 0.8 per cent by $2000 .^{36}$

By 2000, approval for shipments had to comply with s 22 (1) of the Animal Welfare Act 1999 (NZ), which required ensuring adequate water, food and care of animals being transported for any reason, up to the point of disembarkation. Failure to comply with this provision 'without reasonable excuse ${ }^{, 37}$ was considered a strict liability offence which could result in a considerable fine, or possible jail term. ${ }^{38}$ As the standard imposed on exporters became more onerous and the Australian trade boomed, the shipments declined to one per year and a stronger focus on processed meat export began to manifest. ${ }^{39}$ In 2007 , following a report into the conditions of the international abattoirs of New Zealand's importing partners, the Governor-General assented to the Customs Export Prohibition (Livestock for Slaughter) Order 2007. This order expressly prohibited the export of livestock for slaughter without the written permission of the Director-General of the Ministry for Primary Industries. No application for permission has

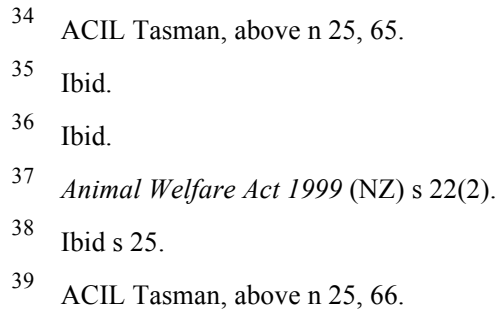


since been made - New Zealand's live animal export trade had been, in a word, slaughtered.

\section{A Model for Australia?}

When asked why the trade has not been banned in Australia, those responsible for live trade policy simply highlight Australia's economic reliance upon the industry. However, recent changes in the Indonesian tariff policy, ${ }^{40}$ a change in the weight limit of all cattle imported, ${ }^{41}$ a plan for selfsufficiency that has cut Indonesian import quotas in half, ${ }^{42}$ and the Indonesian Government reducing export licences by 75 per cent in the third quarter of $2015,{ }^{43}$ all highlight the essential instability of this industry. Notably, 80 per cent of Australia's cattle exports are going to a country (Indonesia), which has indicated that they are determined to end their reliance on Australia. ${ }^{44}$ The Australian agricultural industry does not depend upon staying with live export; rather, it depends upon leaving it. Given the similarities drawn between New Zealand and Australia prior to 2000, the question beckons: can the New Zealand initiatives provide a workable and viable example for Australia?

While shifting away from live export may seem an impossible task, the guide has already been created by New Zealand, a nation whose 'dependence on agriculture exports is far greater than Australia's. ${ }^{45}$ Furthermore, Australia has, in effect, initiated the same framework as found in New Zealand. The

40

Naomi Woodley, 'Indonesia Slaps New Tariff on Cattle Imports, ABC News (online), 19 July 2012, <http://www.abc.net.au/news/2012-07-19/indonesia-slaps-new-tariff-on-cattleimports/4140242>.

41 Matt Brann, 'Live Exports to the Middle East a Big Relief for Northern Pastoralists', $A B C$ Rural (online) 5 June 2012,

$<$ http://www.abc.net.au/rural/news/content/201206/s3518464.htm>.

42 Marie T Hastreiter, 'Animal Welfare Standards and Australia's Live Exports Industry to Indonesia: Creating an Opportunity out of a Crisis' (2013) 12 Washington University Global Studies Law Review 181, 200 citing Colin Bettles, 'Live Exporters' Quota Fears Realised' Farm Weekly, 19 July 2012, 12.

43 Judith Ireland, 'Cattle trade slashed: Labor questions if poor relations with Indonesia are to blame', The Age (online) 14 July 2015, <http://www.theage.com.au/federalpolitics/political-news/cattle-trade-slashed-labor-questions-if-poor-relations-with-indonesiato-blame-20150714-gibkqc>.

44

Hastreiter, above n 5, 200.

45 Geraldine Doogue, Interview with Jim Anderton, former New Zealand Minister for Agriculture and architect of the live export ban (Radio Interview, 18 June 2011):

$<$ http://www.abc.net.au/radionational/programs/saturdayextra/live-animal-trade-the-newzealand-experience/2917316>. 
current Australian Standard for Export of Livestock Version 2.3 (2011) and the Exporter Supply Chain Assurance System ('ESCAS') ${ }^{46}$ are effectively the Australian equivalents of the New Zealand Animal Welfare Advisory Committee Code and Animal Welfare Act 1999 (NZ) respectively. Australia has now reached the point where the decision to end the trade must be made. The imperative is to ensure that appropriate steps towards refocusing and diversifying the agricultural sector can be taken that avoid economic devastation of the industry.

To enable a gradual shutdown of the live animal export industry, the first step that ought to be taken relates to 'diversifying the Australian livestock marketplace. ${ }^{47}$ Australian farmers have demonstrated how quickly progress can be made in this area as seen by their response to the 2011 ban on the trade; Australian farmers adapted to the newly implemented export standards by redirecting resources effectively. If the Australian government adequately supports farmers as they transition from live exports to onshore processed meats ${ }^{48}$ it is likely that a diversified sector will experience similar growth to that experienced by New Zealand. ${ }^{49}$ Furthermore, the increase in onshore processing will require more abattoirs to handle the increase in cattle. Ideally these abattoirs would supply new jobs to the Northern Territory, Queensland, and Western Australia because they are geographically best suited to meat exports. Such an idea has already been proposed. ${ }^{50}$ Ultimately, Indonesia's desire for self-sufficiency has even led to a desire for Australian financial investment and industry expertise. ${ }^{51}$

As the cost of Exporter Supply Chain Assurance System (ESCAS) forces importing nations to look for cheaper alternatives (or pursue selfsufficiency), ${ }^{52}$ the collapse of the Australian live export trade is imminent.

Australian Government Response, Senate Rural Affairs and Transport References Committee July 2012.

47

Hastreiter, above n 5, 201.

48

This processed meat can be shipped to new or existing trade partners when the Indonesian demand slowly declines.

49

Hastreiter, above n 5, 202.

50 Trevor Chappell, 'AACo to Establish Darwin Abattoir' The Advertiser (online) 31 May 2012 ,

$<$ http://www.adelaidenow.com.au/business/aaco-moves-to-build-darwin-abbatoir/storye6frede3-1226375143515>.

51

Ibid.

52 Hastreiter, above n 5, 202. 
While poor animal welfare has long been the cost of this industry, ${ }^{53}$ arguably the two are not at odds with one another; on-shore processing of livestock before export ensures both the survival of the agricultural sector and eliminates the difficulties associated with the regulation of live exports once the animals have left our borders. ${ }^{54} \mathrm{New}$ Zealand has set a laudable example. Brazil, too, has taken similar active steps in this direction.

\section{BRAZIL STRIDES FORWARD}

Brazil exports roughly 600000 head of cattle every year, largely to Lebanon and Venezuela; ${ }^{55}$ a number that is approximately one fourth the size of the Australian industry. While this does not appear to be a particularly significant contribution, the Brazilian contribution in 2004 was only 15000 cattle per year ${ }^{56}$ - which means that there has been an increase of 3400 per cent in under 10 years. Even if this trend plateaus, Brazil represents the only credible threat to Australia's market dominance. Apart from New Zealand, Brazil may be the only nation that can appreciate the animal welfare difficulties consistent with live export trade. Indeed, Brazil recently saw 2700 cattle die from the heat after the Gracia Del Mar was refused entry at port. ${ }^{57}$ The 'abuse and response' pattern experienced by New Zealand and Australia has also tainted the industry in Brazil.

Brazil has acted faster than either Australia or New Zealand, however, because it is bound by a constitutional obligation to 'protect the fauna and the flora, with prohibition, in the manner prescribed by law, of all practices which represent a risk to their ecological function, cause the extinction of species or subject animals to cruelty. ${ }^{58}$ Before considering Brazil's domestic approaches, it is important to note that the European Union ('EU') audit system for all their importers of live animals has the power to suspend the imports from any nation that breaches their welfare and consumption

53 Senate Select Committee on Animal Welfare, above n 14.

54

Doogue, above $\mathrm{n} 45$.

55 Domenico Bazzoni, Americas (2014), Wellard Group

$<$ http://www.wellard.com.au/home/global/americas.html $>$.

56 Hastreiter, above n 5, 198.

57 James Nason, Animal Groups Ramp up Anti-live Export Campaigns (5 March 2012) Beef Central <http://www.beefcentral.com/live-export/animal-groups-ramp-up-anti-live-exportcampaigns $/>$. 
standards. ${ }^{59}$ Therefore, in order to secure the European market, Brazil has consistently expressed an intention to comply with these audits. ${ }^{60}$ The two situations are substantially different; in the EU, the importing nations fear for the welfare of live animals sent from the exporter, whereas in Australian context, the exporting nation fears the conditions found in the importing nation. Nevertheless, the European approach offers an interesting perspective. The collective governments of the EU are willing to suspend the trade entirely in order to meet their desired standards. It may be apt to include a similar measure in Australia's ESCAS.

The Brazilian legislative framework governs the transport and slaughter of all livestock $^{61}$ and ensures welfare in transport to the same current standard as Australia. ${ }^{62}$ In light of the comparatively brief history of the Brazilian live export trade, it is quite remarkable that the legislative scheme implemented by the Brazilian Government (created largely as a disease-prevention method) ${ }^{63}$ should reflect similar animal welfare standards to those of Australia. The EU ranks animal welfare commitments from live animal exporting nations by comparison to their own legislative agendas; the higher the group number, the more negative deviations from the EU standard. ${ }^{64}$ Australia and Brazil rank together in 'Group 3'. In essence, this 'Group 3' standard is reached with only four deviations from EU regulation on the same matter. ${ }^{65}$ Naturally, the closer a nation is to the high standards of the EU, the better. That Australia is in the same grouping as a nation whose live animal export trade is in its infancy, is embarrassing.

59

European Commission Health And Consumers Directorate-General, Final Report of a Mission Carried out in Brazil from 20 January to 2 February, 2009 in Order to Evaluate Food Safety and Public Health Control Systems in Place as well as Certification Procedures in Relation to Export of Beef Meat, (DG(SANCO)/ 2009-8280 - MR - FINAL, 2009) $<$ http://www.google.com.au/url?sa=t\&rct=j\&q=\&esrc=s\&frm=1\&source=web\&cd=1\&ved= 0CBwQFjAAahUKEwjjwKW5xf3IAhVGPKYKHYf9CAo\&url=http\%3A\%2F\%2Fec.euro pa.eu\%2Ffood\%2Ffvo\%2Fact_getPDF.cfm\%3FPDF_ID\%3D7547\&usg=AFQjCNHhRD01 DdX 0ZsQmPIx227WRx8vEQ>.

60 Wangineng UR Livestock Research, Report to Dutch Ministry of Agriculture, Nature, and Food Quality, Animal Welfare in a Global Perspective, 2009.

61 Otto Schmid and Rahel Kilchsperger, Final report deliverable to European Union, Overview of Animal Welfare Standards and Initiatives in Selected EU and Third Party Countries, November 2010, 132-133.

62

Ibid 170

63 Ibid 9.

64 Ibid 10.

65 Ibid 10. 
Brazil appears to suffer the same impediment as Australia - a failure to regulate the killing floors of other nations. However, no reports of mistreatment have arisen in their partner nations at the time of writing. While it is not possible to make an assumption about the future policies of the Brazilian Government, the constitutional entrenchment of animal welfare and their laudable intentions to comply with the high EU standards of welfare, suggest that Brazil will raise the international standard of animal welfare in the live export trade. One notable way of expressing international industry standards is by way of an international treaty.

\section{The Future - A Multilateral Treaty}

The live animal export trade is something of an aberration on the international stage. The very nature of the industry relies upon international cooperation and trade. However, there is no worldwide standard for the treatment of animals, nor an official international instrument endorsed by the international community, other than the World Organisation for Animal Health (Office International des Epizooties or 'OIE'). The OIE, an organisation comprising 180 members including Australia, was established, among other things, 'to provide a better guarantee of food of animal origin and to promote animal welfare through a science-based approach. ${ }^{66} \mathrm{In}$ achieving this end, the OIE has drafted numerous agreements, advisory papers and codes for their member nations to ratify, ${ }^{67}$ including the Terrestrial Animal Health Code ('Animal Code'), which seeks to ensure high 'standards for safe international trade in terrestrial animals ${ }^{68}$ and to secure the 'welfare of food animals during pre-slaughter and slaughter processes, until they are dead. ${ }^{69}$ The Animal Code serves as a guide to member nations, emphasising the need for properly trained persons in all aspects of food animal treatment, and requiring thorough inspections of organisations exporting live animals ${ }^{70}$ and of locations where these animals are slaughtered. ${ }^{71}$ While, at present, the Animal Code is an uncodified, ${ }^{72}$ yet

66 World Organisation for Animal Health, Our Objectives (2015) World Organisation for Animal Health $<$ http://www.oie.int/about-us/our-missions/>.

67 See $<$ http://www.oie.int/about-us/key-texts/basic-texts/>for a complete list.

68 Trade Department, Terrestrial Animal Health Code, (May 2014) World Organisation for Animal Health <http://www.oie.int/international-standard-setting/terrestrial-code/>.

69 Terrestrial Animal Health Code, $23^{\text {rd }}$ ed, World Organisation for Animal Health, Chapter 7.5, Article 7.5.1.1.

70 Ibid, Chapter 7.2, Article 7.2.3.1.

71 Ibid, Chapter 7.5 Article 7.5.1.2. 
ratified, international instrument in Australia, it has little to no effect on the live export practices of the nation or its partner nations. Nevertheless, it has served as a springboard for the creation of Favre's International Convention for the Protection of Animals, ${ }^{73}$ the proposed treaty that is essential to improving the welfare of animals exported alive.

\section{A The Construction of the Treaty}

Favre, a prolific writer on the current status of animals within legal systems and the need for change, ${ }^{74}$ has attempted to find a more appealing solution to the animal welfare problem than that proposed by the radical abolitionists who would ban ownership of animals by humans. ${ }^{75}$ Favre has examined the current OIE standards for animal welfare, and found them wanting. ${ }^{76}$ Not wishing to discount the only current international body to have any real input on the animal welfare discussion, Favre uses the body of principles and recommendations created by the OIE and expands upon them in order to remedy the failure to create 'an actual standard that limits or prohibits practices that are harmful to animal welfare. ${ }^{, 77}$

The lack of any real international regulation of the live animal export trade is an anomaly, but not necessarily a surprising one. The lack of any treaty or international agreement dealing with animal welfare in any way is more than surprising; it is illogical. The proposed International Convention for the Protection of Animals ('ICPA') aims to fill this gap. Unlike the current bilateral agreements between many European nations regarding animals, ${ }^{78}$ and the agreement existing between New Zealand and Switzerland in regard

No domestic legislation has yet been passed to incorporate the code into Australian law.

David Favre, 'An International Treaty for Animal Welfare' (2012) Animal Law 237, 265.

74

David Favre, 'Equitable Self-Ownership for Animals (2000) 50(2) Duke Law Journal 473;

David Favre, 'A New Status for Animals within the Legal System' (2010) 93(3) Marquette Law Review 1021.

75

Gary L Francoine, 'Animals-Property or Persons?' in Cass R Sunstein and Martha C Nussbaum (eds), Animal Rights: Current Debates and New Directions (Oxford University Press, 2005) 108, 134.

76

Favre, above n 73, 252

77 Ibid

78 Nicholas K Pedersen, European Animal Welfare Laws 2003 to Present: Explaining the Downturn (2009), Michigan State University Legal and Historical Centre $<$ https://www.animallaw.info/article/detailed-discussion-european-animal-welfare-laws2003-present-explaining-downturn>. 
to both live animals and their products, ${ }^{79}$ Favre's ICPA would have a similar function to a UN umbrella treaty: 'a framework treaty with the intent to further refine and resolve specific welfare issues in subsequent protocols'. ${ }^{80}$ This would avoid the problem that bedevils most treaty creation and implementation: the near-impossibility of achieving consensus among so many sovereign nations with so many individual cultural and religious practices. Despite these differences, it is hard to imagine nations refusing to agree that a standard of animal welfare must be set, especially when they do not yet have to decide what those standards are. While the proposed treaty appears to be 'empty', it brings the live animal export trade into the realms of international law.

Favre drafted the treaty by balancing the need to attract as many countries as possible while also offering 'provisions that would actually promote animal welfare' ${ }^{81}$ and providing a significant 'enforcement mechanism that has consequences but will not prevent countries from joining the treaty. ${ }^{, 82}$ This was done while following general drafting protocols, such as stating a general policy and defining key words that will be used in the interpretation of further provisions. ${ }^{83}$

The treaty itself is less radical than may appear; it defines different standards of animal welfare for different classes of animals while allowing for changes in the standards applied to each class as their cultural and political significance changes. ${ }^{84}$ The treaty considers all aspects of the animal law conversation, including 'companion' animals, commercial animals and scientific research animals. ${ }^{85}$ While Favre's treaty would no doubt be the largest step forward for animal welfare ever undertaken, in the interests of adoption it is necessary to adjust it to consider only the welfare of live export animals.

79

Agreement between New Zealand and the Swiss Confederation on Sanitary Measures Applicable to Trade in Live Animals and Animal Products, New Zealand - Switzerland, signed 17 November 2010.

80

Favre, above n 73, 252

81 Ibid 256

82 Ibid 256

83 Ibid 256

84 Ibid 257.

85 Ibid 256 


\section{B Adapting the Treaty by Altering the Focus}

The largest animal welfare issue facing Australia relates to the inability to regulate properly the conditions of slaughter in importing nations. Favre's model should therefore be adapted to encompass an international agreement on live export conditions and the treatment of food animals that end up in one nation having originated from another. This new focus may also avoid what Favre sees as the biggest complication with his model: the difficulty of finding a nation state that will justify the 'expenditure of human and financial resources. ${ }^{, 86}$ An umbrella treaty designed purely to deal with live animal export may find a more eager sponsor from the nation state whose government has been under recent pressure to reform the regulation of the trade. A nation such as Australia, for example, could gain significant attention and credibility among its own people and the international community if it were seen to be taking such a significant step in the protection of animal welfare. Similarly, a nation with a booming market such as Brazil could use the treaty to secure trade partners who may be hesitant due to concerns for the welfare of the animals in transit. Alternatively, the nation leading the world in animal welfare concerns in the industry, New Zealand, may wish to adopt the treaty to demonstrate their unwavering commitment to animal welfare.

The protocols under such an umbrella treaty can then be drafted and proposed by these nations. As a 'mini-treaty', ${ }^{87}$ a protocol need not be ratified and codified by every party to the treaty, but only by those that agree. Is this an empty step? What is the purpose of a protocol requiring, for example, OIE standards of slaughter for all imported animals unless all nations agree to ratify the protocol? The answer is simple; it is the easiest option. If the Australian Government were to put forward such a protocol to the treaty to be signed by Australia's trading partners (such as Indonesia), it would be contrary to the intention of the protocol (presumably codified in Australia) to continue the live export trade with any nation (including Indonesia) that does not ratify the protocol. If this protocol were to be adopted by the other major contributors to the trade, namely Brazil, the US ${ }^{88}$ and Uruguay, ${ }^{89}$ those nations refusing to ratify would be starved of live export partners. The ratification requirement may, unfortunately, lead to the perception that some nations dictate or 'bully' others into accepting the terms

86

Ibid 262.

87 Ibid 254

88 Bazzoni, above n 55

89

Ibid. 
they have decided are right. Precedents for such bullying action can be found in nearly any UN trade embargo. If members of the larger international community deem refusal to abide by the international standard as contrary to public policy, then those nations not compliant still have the sovereign choice of complying with the standard or finding an alternate source of food animals. There is no direct threat to a nation's sovereignty.

It is not that an international treaty ought to act as a replacement for the New Zealand model - ending the reliance on an unsustainable industry must be the ultimate goal. A treaty would, however, help to alleviate the concern over animal welfare while the trade is slowly being phased out in favour of preprocessed shipments. Further protocols could then be implemented that ensure the worldwide standard of health and disease prevention that are included within the OIE's Animal Code. ${ }^{90}$

\section{CONCLUSION}

Australian regulation of the welfare of live export trade animals has neither been as effective as that found in New Zealand nor as well-resourced as the one adopted by Brazil. The lack of any international dialogue with other exporters is an enormous oversight on the part of Australian authorities. Reform of the industry is needed soon if the Australian agricultural industry is to survive the exponential growth of the Brazilian industry and the collapse of the Indonesian export market (as Indonesia's demand for live animal export declines). Australia has already started down the same path as New Zealand. Its legislative scheme currently mirrors the New Zealand scheme from the late 1990s and early 2000s. With adequate Government support, Australian farms have the capacity to shift their reliance from live export to a pre-processed industry, at which point the live export industry could be banned permanently in Australia. It is imperative that this transition process commences as a matter of urgency, lest the agriculture sector be devastated by changing markets internationally.

New legislation, coupled with the significant financial investment exemplified in Brazil's regulation of the industry, serves as a viable route for reform of the Australian trade. While constitutionally entrenching animal welfare is not necessarily required, further financial investment in animal welfare research and an expressed desire to reach and maintain EU-level standards of welfare are important steps that must be taken by the Australian 
government. If the world's two largest live animal exporters express the same intention to reach the same level of animal welfare, there can be no fear of one nation compromising the other's market dominance.

In the interests of international cooperation, a treaty based upon Favre's proposal should be pursued as the minimum standard between Australia and Brazil, with the aim of bringing the international community ultimately into the fold. Beginning as a simple agreement on the standards required during transport, this treaty could, one day, lead to protocols alienating from the trade any nations that do not subscribe to desired killing floor standards. While this seems to be a moot point in a post-live animal export Australia, it would show an unprecedented commitment to animal welfare and would place Australia as the leader in the ever-changing world of animal law. 